\title{
The Role of Depression on Glycemic Control
}

\author{
Elisabete Rodrigues Nascimento ${ }^{\mathrm{a}, \mathrm{c}}$, Antonio Egidio Nardi ${ }^{\mathrm{a}, \mathrm{b}}$, Adriana Cardoso ${ }^{\mathrm{a}, \mathrm{b}}$
}

\begin{abstract}
Diabetes mellitus (DM) is a chronic disease with clinical complications and is responsible for many hospital stays. The complications of DM are related to hyperglycemia and other related diseases. Comorbidity of depression decreases glycemic control due to a depressed mood that interferes with self-care, as an irregularity in the low-glycemic index diet, prescribed medication and lack of physical activity.
\end{abstract}

Keywords: Diabetes mellitus; Glycemic control; Self-care; Depression

\section{Introduction}

Diabetes mellitus type 2 (DM2) is an important risk factor for cardiovascular disease (CVD). The CVDs are responsible for $80 \%$ of the deaths in these patients. Diabetics are three times higher risk of death from CVD compared to the general population [1].

The DM2 is characterized by insulin resistance and secretion of hormones deficiency. The increase of glucose in the bloodstream causes several serious symptoms, such as weight loss or significant increase, sensations of cold and heat, pain, cardiac, among others, generating the need for self-monitoring of blood glucose several times 1 day [2].

The central component in the treatment of DM is self-care. Disease management requires a comprehensive approach that includes changes in lifestyle: changes of eating habits, physi-

Manuscript accepted for publication November 27, 2014

anstitute of Psychiatry, Federal University of Rio de Janeiro (IPUB/UFRJ), Brazil

bNational Institute of Science and Technology for Translational Medicine (INCT-TM/CNPq), Brazil

${ }^{\mathrm{c} C o r r e s p o n d i n g ~ A u t h o r: ~ E l i s a b e t e ~ R o d r i g u e s ~ N a s c i m e n t o, ~ I n s t i t u t e ~ o f ~ P s y c h i a-~}$ try, Federal University of Rio de Janeiro, Laboratory of Panic and Respiration, INCT Translational Medicine, R Visconde de Piraja, 407/702, Rio de Janeiro, RJ 22410-003, Brazil. Email: bete_nascimentopsi@ig.com.br

doi: http://dx.doi.org/10.14740/jem247w cal activities, watching your feet and the use of medications on a regular basis. For these reasons, many patients with DM2 may develop changes in mood and even depression [3].

The DM and depression often occur in comorbidity $[4,5]$. In diabetic patients the depression has been linked with poor glycemic control and low adherence to self-care activities. The lack of self care in diabetics is seen as one of the explanations for depression-related hyperglycemia [6].

The Multi-Ethnic Study on Atherosclerosis (MESA) investigated the incidence of DM2 in 5,201 diabetics during a period of 3.2 years, and noted that individuals with high rate of depression showed risk 1.42 times of occurrence of DM2. The depression risk factor for diabetics was linked to lifestyle, such as eating habits, physical inactivity and smoking [7].

This mental disorder may precede or follow the start of diabetes complications depending on the individual or the course of the disease [8]. Therefore, knowing the impact of depression can be beneficial to guide therapeutic intervention targeted to depressed diabetics, and it is very important. The evidence from controlled studies suggests that the diagnosis and treatment of depression may lead to an improvement in the evolution of these individuals [9].

\section{Depression and Glycemic Control}

The neurochemical and hormonal changes present depression that cause hyperglycemic effects, and glycemic metabolism disorders may result. The increased activity of the hypothalamic pituitary adrenal glands and the sympathetic nervous system, results in increased release of cortisol and release of catecholamine. Also, epinephrine and norepinephrine can lead to increased blood sugar via decreased insulin synthesis or increased peripheral resistance to insulin action [3].

Depression in patient with diabetes has been suggested as one of the possible causes of poor metabolic control. In 2002, Martins et al [10] observed poorer control of blood glucose and glycated hemoglobin (HbAlc) among diabetic women with depression compared to non-depressed, showing the negative effect of depression on adherence to treatment and risk of complications of DM2.

The study of Papelbaum and colleagues showed that patients with DM2 depression showed higher levels of HbA1c when compared with those who did not present mood disorder. 
The authors observed still high rate of depression in individuals who made use of insulin as compared to patients who used oral hypoglycemic [11].

These authors showed that diabetics with depression have attitudes that result in a negative impact on fasting glucose and HbA1c, whether by difficulties with regard to changing habits of life, as well as presenting greater body mass index and smoking.

The symptoms of depression are related to decreased adherence to dietary guidelines, greater risk of interruption in the use of medications, and worst overall operation contributing to the possible difficulty of change of habit and the capillary glycemic, insulin application and control of hyperglycemic diet. A meta-analysis containing 47 independent studies demonstrated that depression in patients with DM was significantly associated with non-adherence to treatment. There was a negative effect for patients with DM with depressive symptoms in the absence of medical consultations attendance [12]. In addition, it has been shown that diabetic adults with little humor changes respond to programs intended for weight control and smoking cessation, among others. Also the functional impairment associated with an increase in symptoms of depression, in turn, would make it even more functional style modifications related to the low quality of life of individuals with DM2 $[5,10]$. The adherence to treatment is important to reduce the risk of complications of DM. Thus, the appropriate use of prescription drugs, such as oral medications and insulin, as well as a healthy diet and exercise, is fundamental to the adequate control of blood glucose.

\section{Conclusion}

The impact of depression may influence the clinical course of the DM2. Diabetics with mood present difficulty to daily glycemic monitoring, implementation of physical exercise, diet control and lack of adherence to the medication. Therefore, depression can contribute to poor glycemic control in the treatment of individuals with DM2.

\section{References}

1. Silva RCP, Simoes MJS, Leite AA. Risk factors for cardiovascular diseases in the elderly with type 2 diabetes mellitus. Rev Cienc Farm Basica Apl. 2007;(1):113-121.

2. Eaton WW, Mengel M, Mengel L, Larson D, Campbell R, Montague RB. Psychosocial and psychopathologic influences on management and control of insulin-dependent diabetes. Int J Psychiatry Med. 1992;22(2):105-117.

3. Moreira RO, Papelbaum M, Appolinario JC, Matos AG, Coutinho WF, Meirelles RMR. Diabetes and Depression: a systematic review. Arq Bras Endocrinol Metab. 2003;47(1):19-29.

4. Knol MJ, Heerdink ER, Egberts AC, Geerlings MI, Gorter KJ, Numans ME, Grobbee DE, et al. Depressive symptoms in subjects with diagnosed and undiagnosed type 2 diabetes. Psychosom Med. 2007;69(4):300-305.

5. de Ornelas Maia AC, Braga Ade A, Paes F, Machado S, Carta MG, Nardi AE, Silva AC. Comorbidity of depression and anxiety: association with poor quality of life in type 1 and 2 diabetic patients. Clin Pract Epidemiol Ment Health. 2013;9(136-141.

6. Peyrot M, McMurry JF, Jr., Kruger DF. A biopsychosocial model of glycemic control in diabetes: stress, coping and regimen adherence. J Health Soc Behav. 1999;40(2):141158.

7. Golden SH, Lazo M, Carnethon M, Bertoni AG, Schreiner PJ, Diez Roux AV, Lee HB, et al. Examining a bidirectional association between depressive symptoms and diabetes. JAMA. 2008;299(23):2751-2759.

8. Roy MS, Roy A, Affouf M. Depression is a risk factor for poor glycemic control and retinopathy in African-Americans with type 1 diabetes. Psychosom Med. 2007;69(6):537-542.

9. Collins MM, Corcoran P, Perry IJ. Anxiety and depression symptoms in patients with diabetes. Diabet Med. 2009;26(2):153-161.

10. Martins GL, Tanaka RM, Campos NB, Dalbosco IS. Prevalence of depression in women with type 2 diabetes mellitus in postmenopausal. Arq Bras Endocrinol. 2002;46(6):674-678.

11. Papelbaum M, Moreira RO, Coutinho W, Kupfer R, Zagury L, Freitas S, Appolinario JC. Depression, glycemic control and type 2 diabetes. Diabetol Metab Syndr. 2011;3(1):26.

12. Ciechanowski PS, Katon WJ, Russo JE. Depression and diabetes: impact of depressive symptoms on adherence, function, and costs. Arch Intern Med. 2000;160(21):32783285. 